\title{
HIV/AIDS: nutritional implications and impact on human development
}

\author{
Esi Colecraft \\ ENAM Project, Department of Food Science and Human Nutrition, Iowa State University, Ames, Iowa 50011-1061, USA
}

\begin{abstract}
HIV/AIDS is associated with biological and social factors that affect the individual's ability to consume and utilize food and to acquire food. These biological and social factors lead to poor nutritional status and weight loss, which are an important cause of morbidity in individuals infected with HIV, resulting in a poor quality of life; weight loss is an important predictor of death from AIDS. The links between nutrition and HIV/AIDS amplify the negative effects of HIV infection on human development at individual, household, community and national levels. For many developing countries the incidence of HIV/AIDS and malnutrition is impeding progress towards achieving the UN millennium development goals. Aggressive interventions to curb the spread of HIV continue to be needed. Concurrent efforts to improve nutrition for populations living with HIV/AIDS should also be given priority.
\end{abstract}

Millennium development goals: HIV infection: Nutrition and HIV/AIDS

The synergistic relationship between nutrition and the immune system has long been recognized ${ }^{(1,2)}$. However, the advent of HIV/AIDS has brought the discussion of nutrition and immune function to prominence in recent times. In the past, the relationship between nutrition and infections has emphasized the vulnerabilities and risks of children, while with HIV/AIDS the discussion permeates all stages of life.

The interaction between nutrition and HIV/AIDS has biological and social consequences; impacts that affect the individual, household, community and nations. While research is still needed to better understand these processes, the evidence available suggests that nutrition, a key component of developmental processes, cannot be ignored in the fight against HIV/AIDS.

The present article provides a synopsis of the interaction between nutrition and HIV/AIDS and its implications for achieving the UN millennium development goals $(\mathrm{MDG})^{(3)}$.

\section{The vicious cycle of HIV/AIDS and malnutrition}

Malnutrition and HIV have similar deleterious effects on the immune system ${ }^{(4-6)}$. In both malnutrition and HIV there is reduced CD4 and CD8 T-lymphocyte numbers ${ }^{(7,8)}$, delayed cutaneous sensitivity, reduced bacteriocidal properties $^{(5)}$ and impaired serological response after immunizations $^{(9,10)}$. The synergistic effects of malnutrition and
HIV on the immune system occur in a vicious cycle (Fig. 1) in which the decreased immunity associated with both conditions leads to increased susceptibility to infections (including HIV infection) that in turn lead to increased nutrient requirements, which if not adequately met lead to more malnutrition ${ }^{(11,12)}$. Malnutrition, specifically wasting, is an important predictor of HIV progression to $\operatorname{AIDS}^{(13)}$.

\section{HIV and malnutrition}

The causes of malnutrition in HIV include: inadequate dietary intakes; nutrient loses; metabolic changes; increased requirements $^{(14,15)}$.

\section{Inadequate dietary intake}

HIV is associated with biological factors such as loss of appetite, gastrointestinal complications and oral and oesophageal sores that affect the individual's desire for food and ability to eat, leading to inadequate dietary intakes $^{(8,11)}$. In developing countries these biological effects are exacerbated by the social consequences of the disease, which typically culminate in food insecurity. Households affected by HIV/AIDS confront severe declines in the availability of food (both quantity and quality) because of a decrease or complete loss of the socio-economic contributions of sick household member(s) 


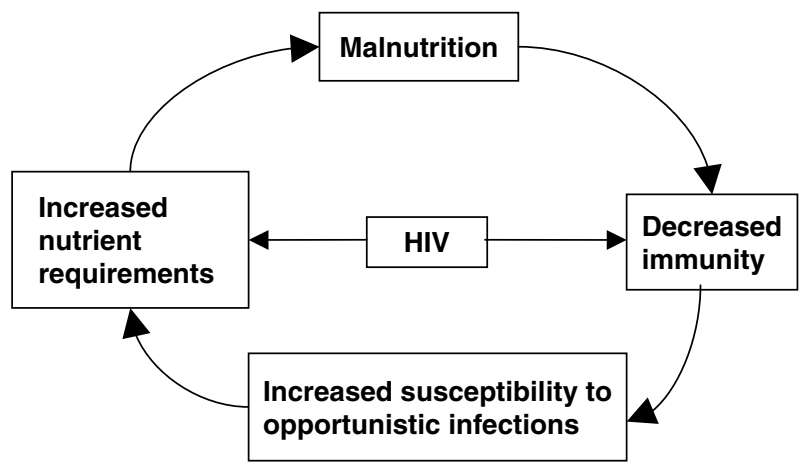

Fig. 1. Vicious cycle of HIV and malnutrition. (From Edwards ${ }^{(23)}$.)

as well as their caregivers ${ }^{(16)}$. Lack of social support as a result of stigmatization and discrimination also contributes to reduced food availability and hence inadequate dietary intakes by those affected by $\mathrm{HIV}^{(17)}$.

\section{Nutrient losses}

Such losses are usually a result of malabsorption and/or diarrhoea $^{(11)}$. Malabsorption may be caused by changes in the intestinal lining resulting from the infection ${ }^{(18)}$. It has been reported that poor absorption of carbohydrates and fats can occur at any stage of HIV infection in both adults and children, so that even asypmptomatic individuals can exhibit malabsorption ${ }^{(11)}$, which leads to excess nutrient losses. Poor absorption of fat reduces absorption of the fat-soluble vitamins such as vitamin $A$ and $E^{(12)}$. Diarrhoea and vomiting can result from opportunistic infections and are also common side effects of HIV medications ${ }^{(19)}$.

\section{Metabolic changes}

The immune system's response to HIV infection leads to metabolic changes that promote protein catabolism (associated with muscle wasting) and changes in fatty acid metabolism. During the acute-phase response pro-oxidant cytokines are produced, leading to increased utilization of antioxidant vitamins ${ }^{(20)}$. Minerals such as Fe, Zn, Se and $\mathrm{Cu}$ are also sequestered for the production of antioxidant enzymes ${ }^{(21,22)}$. The immune response may also induce loss of appetite coupled with fever ${ }^{(22)}$. The metabolic changes associated with HIV infection lead to increased energy and protein requirements together with inefficient utilization of nutrients $^{(23)}$.

\section{Increased requirements}

The consequence of nutrient loses and changes in metabolism in HIV infection is increased requirements for both macro- and micronutrients. Energy requirements are elevated at different stages of the disease. Even during the asymptomatic phase there is a $10 \%$ increase in energy requirement above the level of intake recommended for a healthy individual of the same age, gender and physical activity level who is HIV negative; in the symptomatic phase the corresponding increase is $20-30 \%{ }^{(15)}$.
Deficiencies in some micronutrients are common in individuals infected with $\mathrm{HIV}^{(20,24,25)}$. According to the WHO dietary intake of micronutrients at RDA levels may not be adequate to correct nutritional deficiencies in individuals infected with $\mathrm{HIV}^{(15)}$; however, some micronutrient supplements have been shown to produce adverse outcomes in populations infected with HIV.

\section{HIV-related wasting}

The most common physical sign of nutrition inadequacy in HIV/AIDS is weight loss. The pattern of weight loss in individuals infected with HIV has been shown to be different from that of a healthy individual suffering from an acute illness ${ }^{(11)}$. When an individual who is not infected with the HIV virus experiences an illness there is a proteinsparing effect in which fat stores are the first to be broken down to meet the elevated energy requirements associated with the illness. In HIV infection the opposite is true; body proteins are more likely to be the first to be broken down, to provide amino acids to fuel energy needs ${ }^{(18)}$. Two patterns of weight loss have been observed in HIV: acute or rapid weight loss from secondary or opportunistic infections; chronic or slow weight loss from anorexia and gastrointestinal disease ${ }^{(26)}$.

Weight loss is associated with significant morbidity and mortality in populations living with HIV/AIDS. A $5 \%$ loss in weight is associated with risk for wasting, mortality and opportunistic infections ${ }^{(27)}$. A weight loss of $\geq 10 \%$ is used to define wasting syndrome; a condition typically found in adult patients with AIDS in Africa ${ }^{(11,28)}$. Hospitalization usually occurs when there is a $20 \%$ loss in weight in the presence of opportunistic infections $^{(23)}$.

\section{HIV/AIDS, malnutrition and human development}

The effects of malnutrition and HIV are synergistic and so they amplify their individual deleterious effects. Malnutrition exaggerates the effects of HIV on the individual by promoting fatigue and disease progression, resulting in increased morbidity and earlier death ${ }^{(16)}$. In the social context malnutrition aggravates the negative effects of HIV/AIDS on food and nutrition security ${ }^{(16)}$. Food security refers to physical and economic access to food in sufficient quality and quantity, while nutrition security is defined as secure access to food coupled with a sanitary environment, adequate health services and adequate care to ensure a healthy life for all household members ${ }^{(16)}$. The interaction between HIV/AIDS and food and nutrition security has been described as a vicious cycle in which food insecurity increases susceptibility to HIV exposure and infection and HIV/AIDS in turn increases vulnerability to food insecurity $^{(29)}$. For many developing countries the effects of HIV/ AIDS on food and nutrition security as well as other social effects of the disease impede progress to achieving the $\mathrm{MDG}^{(30)}$. How the interaction between HIV/AIDS and malnutrition encumbers each of the MDG will be briefly discussed. 


\section{Millennium development goal 1: eradicate extreme poverty and hunger}

HIV/AIDS-related morbidity and mortality coupled with malnutrition leads to a decline or loss in the productive capacity of individuals and households, resulting in a decline or complete loss of household income ${ }^{(16,30,31)}$. Concurrently, families affected by HIV experience increased household expenses as a result of increased healthcare costs ${ }^{(30,32)}$. Household assets are often sold to offset these effects ${ }^{(33)}$. The end result is more poverty and more food insecurity, and that moves households, communities and nations away from, rather than towards, achieving MDG1. Children whose parents die of AIDS have few or no assets, and therefore the effects of HIV/ AIDS on poverty and hunger extend to future generations $^{(34)}$.

\section{Millennium development goal 2: achieve universal primary education}

HIV/AIDS affects both the 'supply' and 'demand' side of education $^{(30)}$. On the supply side, AIDS may cause absenteeism and mortality of teachers and other staff, thus lowering the availability and quality of learning opportunities for children ${ }^{(35)}$. On the demand side, HIV/AIDS-associated poverty limits parents' ability to pay school fees ${ }^{(30)}$. In addition, children may be required to drop out of school to contribute economically to their households or assist in providing care for sick household members. Children orphaned through HIV/AIDS who live with distant relatives or unrelated caregivers have lower school enrolment rates $^{(16)}$. The capacity of children to learn may also be hindered because children from homes affected by HIV/ AIDS may lack adequate nutrition for optimal cognitive development.

\section{Millennium development goal 3: promote gender equality and empower women}

The target associated with this goal is to eliminate gender disparity in primary and secondary education, preferably by 2005, and in all levels of education no later than $2015^{(3)}$. HIV/AIDS presents several challenges that can slow down progress in achieving this goal. In much of the developing world the prevalence of HIV is higher for women than for men, and women are more likely than men to be infected at younger ages ${ }^{(25,36)}$. Thus, women are more vulnerable to the negative effects of HIV/AIDS on school enrolment, attendance and completion. HIV/AIDS therefore perpetuates gender inequality and women's powerlessness by limiting women's access to education $^{(17,37)}$

\section{Millennium development goal 4: reduce child mortality}

HIV/AIDS contributes directly and indirectly to child mortality and thus is a major limitation to achieving this goal. Among the children $60 \%$ of those who contract HIV during the perinatal period die before the age of 5 years ${ }^{(30)}$. It is reported that the mean survival time for children who are HIV positive is 3 years $^{(38)}$. Indirectly, HIV contributes to child deaths through maternal HIV status ${ }^{(30,38)}$. Children born to mothers who are HIV positive are more likely to die than those born to mothers who are HIV negative ${ }^{(39)}$. The effects of HIV/AIDS on achieving MDG4 include issues related to: mother-to-child transmission and child survival $^{(16)}$; infant and young child feeding in the face of maternal HIV infection ${ }^{(25)}$; adult (especially mothers) HIV mortality and child well-being and survival ${ }^{(39,40)}$.

\section{Millennium development goal 5: improve maternal health}

An indicator for this goal is maternal mortality ratio. HIV/ AIDS presents additional risks to mothers, thus hampering progress towards this goal. HIV infection is associated with higher risks of prenatal and child-birth complications, including miscarriage, anaemia and postpartum haemorrhage, which are important causes of maternal deaths ${ }^{(41)}$. HIV also increases risk of infections such as malaria and pneumonia $^{(30)}$.

\section{Millennium development goal 6: combat HIV/AIDS, malaria and other diseases}

Progress in this goal is likely to have an important impact on all the other MDG. The relationship between nutrition and immunity suggests that nutrition interventions are key to making progress in this goal.

\section{Millennium development goals 7 and 8: ensure environmental sustainability and develop global partnership for development}

Although these issues are key issues, other pressing issues induced by HIV distract attention from these goals.

\section{Conclusions}

The effect of HIV/AIDS on human development is captured in the following quote from the 2005 WHO consultative meeting on Nutrition and HIV/AIDS held in Durban, South Africa: 'HIV/AIDS is affecting more people in Eastern and Southern Africa than our fragile health systems can treat, demoralizing more children than our educational systems can inspire, creating more orphans that our communities can care for, wasting families, threatening food systems. The HIV/AIDS epidemic is increasingly driven by and contributes factors that also create malnutrition, in particular poverty, ${ }^{(42)}$.

It is apparent that aggressive efforts to combat the spread of HIV/AIDS continue to be needed in much of the developing world, otherwise progress towards all the MDG will be frustrated. However, interventions to prevent and treat HIV/AIDS and to mitigate the social effects of the disease need to take into consideration the interaction between HIV/AIDS and nutrition. At the individual level nutrition therapy and related interventions contribute to the fight against HIV/AIDS by delaying the progression of HIV to AIDS, preventing mother-to-child transmission of the virus, preventing serious infections in individuals who are HIV positive and altering the severity and outcome of infections. Additionally, nutrition interventions 
can mitigate the social impacts of HIV/AIDS. Thus, the following quote by William Clay of FAO's Food and Nutrition Division may well be justified: 'Food isn't a magic bullet. It won't stop people from dying of AIDS but it can help them live longer, more comfortable and productive lives ${ }^{\text {(43). }}$.

\section{References}

1. Scrimshaw N, Taylor C \& Gordon J (1968) Interactions of Nutrition and Infection. Geneva: WHO.

2. Scrimshaw NS \& SanGiovanni JP (1997) Synergism of nutrition, infection and immunity: An overview. Am J Clin Nutr 66, 464S-477S.

3. United Nations (2006) The Millenium Development Goals Report. New York: UN.

4. Jain VK \& Chandra RK (1984) Does nutritional deficiency predispose to acquired deficiency syndrome? Nutr Res 4, 537-543.

5. Beisel WR (1996) Nutrition and immune function: Overview. J Nutr 126, 2611S-2615S.

6. Piwoz EG (2004) Nutrition and HIV/AIDS: evidence, gaps, and priority actions. http://sara.aed.org/publications/cross_ cutting/hiv_nutrition/HIV-Nutrition_\%20brief.pdf

7. Chandra RK (1999) Nutrition and immunology: from clinic to cellular biology and back again. Proc Nutr Soc 58, 681683.

8. Suttajit M (2007) Advances in nutrition support for quality of life in HIV/AIDS. Asia Pac J Clin Nutr 16, Suppl., 318-322.

9. Faulk WP, Demaeyer EM \& Davis AJS (1974) Some effects of malnutrition on the immune response in man. Am J Clin Nutr 27, 638-646.

10. Kroon FP, van Dissel JT, de Jong JC \& van Furth R (1994) Antibody response to influenza, tetanus, and pneumococcal vaccines in HIV-seropositive individuals in relation to the number of CD4 lymphocytes. AIDS 8, 469-476.

11. Piwoz EG \& Preble EA (2000) HIV/AIDS and Nutrition: A Review of the Literature and Recommendations for Nutritional Care and Support in Sub-Saharan Africa. Washington, DC: Support for Analysis and Research in Africa (SARA) Project Bureau for Africa, Office of Sustainable Development and USAID; available at http://pdf.usaid.gov/pdf_docs/ PNACK673.pdf

12. Semba RD \& Tang AM (1999) Micronutrients and the pathogenesis of human immunodeficiency virus infection. Br J Nutr 81, 181-189.

13. Malvy D, Thiébaut R, Marimoutou C \& Dabis F (2001) Weight loss and body mass index as predictors of disease progression to AIDS in adults. Aquitaine Cohort, France, 1985-1997. J Am Coll Nutr 20, 609-615.

14. Macallan DC (1999) Wasting in HIV infection and AIDS. J Nutr 129, 238S-242S.

15. World Health Organization (2003) Nutrient Requirements for People Living with HIV/AIDS: Report of a Technical Consultation. Geneva: WHO.

16. Gillespie S \& Kadayila S (2005) HIV/AIDS and Food and Nutrition Security: From Evidence to Action. Food Policy Review no. 7: Washington, DC: IFPRI.

17. Drimie S, Getahun T \& Frayne B (2006) RENEWAL Ethiopia Background Paper: HIV/AIDS, Food Security and Nutrition Security. Washington, DC: IFPRI.

18. Hsu JWC, Pencharz PB, Macallan D \& Tomkins A (2005) Macronutrients and HIV/AIDS: A Review of Current Evidence. Geneva: WHO; available at http://www.who.int/ nutrition/topics/Paper_1_Macronutrients_bangkok.pdf
19. Chen D, Misra A \& Garg A (2002) Lipodystrophy in human immunodeficiency virus-infected patients. J Clin Endocrinol Metab 87, 4845-4856.

20. Friis H (2005) Micronutrients and HIV Infection: A Review of Current Evidence. Geneva: WHO; available at http:// www.who.int/nutrition/topics/Paper\%20Number\%202\%20-\% 20Micronutrients.pdf

21. Enwonwu C (2006) Complex interactions between malnutrition, infection and immunity: relevance to HIV/AIDS infection. Niger J Clin Biomed Res 1, 1-14.

22. Bogden JD \& Oleske JM (2007) The essential trace minerals, immunity, and progression of HIV infection. Nutr Res 27, 69-77.

23. Edwards C (2006) Nutritional implications of HIV/AIDS Powerpoint presentation: http://jamiacanap.org/Treatment\% 20Care $\%$ Nutrition $\%$ Nutritiona $\% 20$ Implications $\% 20$ of $\% 20 \mathrm{HIV}$. ppt (accessed July 2007).

24. Fawzie W (2003) Micronutrients and human immunodeficiency virus type 1 disease progression among adults and children. Clin Infect Dis 37, S112-S116.

25. Piwoz EG \& Bentley ME (2005) Women's voices, women's choices: The challenge of nutrition and HIV/AIDS. $J$ Nutr 135, 933-937.

26. Macallan DC, Noble C, Baldwin C, Foskett M, McManus T \& Griffin GE (1993) Prospective analysis of patterns of weight change in stage IV human immunodeficiency virus infection. Am J Clin Nutr 58, 417-424.

27. Wheeler DA, Gilbert CL, Launer CA, Muurahainen N, Elion RA, Abrams DI \& Bartsch GE (1998) Weight loss as a predictor of survival and disease progression in HIV infection. J Acquir Immune Defic Syndr 18, 80-85.

28. World Health Organization (2005) Interim WHO Clinical Staging of HIV/AIDS and HIV/AIDS Case Definitions for Surveillance: African Region. Geneva: WHO; available at http://www.who.int/hiv/pub/guidelines/clinicalstaging. pdf

29. Gunter H (2003) Food Security and HIV: An Update. Rome: FAO; available at http://www.fao.org/DOCREP/MEETING/ 006/Y9066e/Y9066e00.HTM

30. Alban A \& Anderson NB (2005) Putting it together: AIDS and the Millennium Development Goals. http://www.iavi.org/ file.cfm?fid $=33078$

31. Gillespie S, Haddad L \& Jackson R (2001) HIV/AIDS, food and nutrition security: impacts and actions. In Nutrition and HIV/AIDS, Nutrition Policy Discussion Paper no. 20, pp. 31-46. Geneva: UN ACC/SCN; available at http:// www.unsystem.org/SCN/Publications/NPP/npp20.PDF

32. O'Donnell M (2004) Food Security, Livelihoods and HIV/ AID: A Guide to the Linkages, Measurements and Programming Implications. London: Save the Children.

33. Barnett A \& Rugalema G (2001) HIV/AIDS. International Food Policy Research Institute 2020 Focus no. 05, Brief no. 09. Washington, DC: IFPRI.

34. Bell C, Devarajan S \& Gersbach H (2004) Thinking about the long-run economic costs of AIDS. In The Macroeconomics of HIV/AIDS, pp. 96-133 [M Haacker, editor]. Washington, DC: IMF; available at http://www.imf.org/ external/pubs/ft/AIDS/eng/chapter3.pdf

35. Grassly NC, Kamal D, Pegguri E, Sikazwe A, Malambo I, Siamatowe C \& Bundy D (2003) The economic impact of HIV/AIDS on the education sector in Zambia. AIDS 17, 1039-1044.

36. Joint United Nations Programme on AIDS (1999) Gender and HIV/AIDS: Taking Stock of Research and Programs. Best Practice Collection no. BP007. Geneva: UNAIDS; available at http://www.unaids.org/publications/documents/ human/gender/una99e16.pdf 
37. Joint United Nations Programme on HIV/AIDS/United Nations Population Fund/United Nations Development Fund for Women (2004) Women and HIV/AIDS: confronting the crisis. A joint report by UNAIDS/UNFPA/UNIFEM. http://www.unfpa.org/hiv/women/report/index.htm

38. Newell M, Brahmbhatt H \& Ghys P (2004) Child mortality and HIV infection in Africa: a review. AIDS 18, Suppl. 2, $7-34$.

39. Urassa MJ, Boerma R, Isingo J, Ngalula J, Ng'Weshemi J, Mwaluko G \& Zaba B (2001) The impact of HIV/AIDS on mortality and household mobility in rural Tanzania. AIDS 15, 2017-2023.

40. Deininger K, Garcia M \& Subbarao K (2003) AIDSinduced orphanhood as a systemic shock: Magnitude, impact and program interventions in Africa. World Dev 31, 12011220.

41. World Health Organization (2005) The World Health Report 2005: Making Every Mother and Child Count. Geneva: WHO.

42. World Health Organization (2005) ANNEX WHO consultation on Nutrition and HIV/AIDS in Africa. http://www. who.int/nutrition/topics/Participants'\%20Statement\%20-\%20 EB116.pdf

43. Food and Agriculture Organization (2003) News detail. Take two tablets after the meals, but don't forget the meals: it can help delay the onset of AIDS. http://www.fao.org/ world/regional/rap/news_detail.asp?event_id=25530\&year=2003 (accessed October 2007). 